Ciência e Natura, Santa Maria, v. 37 n. 3 set-dez. 2015, p. 796-807

Revista do Centro de Ciências Naturais e Exatas - UFSM

ISSN impressa: 0100-8307 ISSN on-line: 2179-46017245

\title{
ciênciaenatura
}

\section{Seminário Integrado e Projetos de Aprendizagem: uma proposta metodológica para a construção de saberes}

\author{
Integrated Seminar and Learning Projects: a methodological proposal for the construction of \\ knowledge
}

Everton Bedin ${ }^{12}$, José Claudio Del Pino

Universidade de Passo Fundo, Universidade Federal do Rio Grande do Sul

\begin{abstract}
Resumo
Este ensaio traz à tona ponderaçães de um estudo realizado à luz da inserção das Tecnologias de Informação e Comunicação (TICs) e adaptação da Metodologia de Projetos de Aprendizagem (PAs) na disciplina de Seminário Integrado (SI), na realidade da modalidade de Ensino Médio Politécnico (EMP). Desta forma, este artigo tem por intuito apresentar as concepções que os estudantes do segundo ano do EMP carregam no viés de imagens sobre a temática ambiental, a fim de construir, por meio da metodologia supracitada no viés das TICs, projetos científicos de pesquisa. O estudo realizado foi de caráter qualitativo. A coleta de dados foi realizada dentro do ambiente de aprendizagem; logo, com observação e diálogos via apresentação de um plano de aula. Nesta perspectiva, verificou-se que os estudantes, quando instigados a trocar saberes do contexto com a temática de Sustentabilidade Ambiental, caracterizam-na de forma espiritual, tecnológica e, dentre outros, familiar. Destarte, observou-se que os estudantes, quando trabalham em grupo, desenvolvem projetos científicos, constroem e reconstroem saberes sobre Sustentabilidade Ambiental e tornam-se autores da própria aprendizagem.
\end{abstract}

Palavras-chave: Tecnologia da Informação e Comunicação, Projeto de Aprendizagem, Saberes.

\begin{abstract}
This test brings up weights of one study carried out in the light of the integration of Information and Communication Technologies (ICTs) and adaptation of Learning Projects Methodology (PAs) in the discipline of Integrated Seminar (SI) in reality mode Polytechnic High School $(E M P)$. Thus, this article is meant to present the concepts that the students of the second year of the EMP carry the pictures bias on environmental issues, to construct through the above methodology in the bias of ICTs, scientific research projects. The study was qualitative. Data collection was performed within the learning environment; soon with observation and dialogues via presentation of a lesson plan. In this perspective, it was found that the students, when urged to change the context of the knowledge-themed Environmental Sustainability, characterized in a spiritual way, technological and, among others, family. Thus, it was observed that the students, when working in a group, develop scientific projects, construct and reconstruct knowledge on Environmental Sustainability and become authors of their own learning.
\end{abstract}

Keywords: Information and Communication Technology, Learning Project, Knowledge. 


\section{Introdução}

$\mathrm{V}$ ivendo-se em uma era tecnológica, torna-se crucial a necessidade do professor acoplar às suas metodologias de ensino as Tecnologias da Informação e Comunicação (TICs) seja em ambientes formais ou não formais, de modo a qualificar o conhecimento do aluno, ressignificar seus saberes a partir do conhecimento científico, maximizar a forma de buscar informações, tornando os processos de ensino e de aprendizagem de forma fácil e ágil, além de qualificar a relação entre o professor e estudante.

Do mesmo modo, torna-se necessário uma reflexão sobre a prática docente, favorecendo o uso de novas tecnologias no ensino, pois, muitas vezes, tem-se conhecimento de que, dependendo da forma com que as TICs são usadas pelo professor, podem-se derivar em exacerbadas fragmentações entre a teoria e a prática seja na maneira de expor ou explicar um conteúdo, ou posteriormente, faz com que nasça a dicotomização entre o dizer e o fazer das práticas pedagógicas.

Neste desenho, tem-se em mente que muitos profissionais da educação, nas atividades diárias de sala de aula, relacionam os saberes científicos ao contexto do educando por meio das TICs apenas como comprovação ou suporte de ensino na exposição individual ou coletiva, mas não refletem sobre o real sentido de sua utilização ora pela falta de objetivos sobre os conteúdos ora por não saber qual a forma exata de conectá-las no momento pedagógico.

Desta forma, torna-se necessário compreender o verdadeiro significado de tramar um ambiente de aprendizagem com o uso das tecnologias. De antemão, o profissional deve planejar claramente sua aula para a inserção das tecnologias, ser flexível, ter em mente seus objetivos e dominar, antes de tudo, o conteúdo específico a ser trabalhado. Portanto, o profissional da educação precisa dominar, necessariamente, a forma de como trabalhar com a tecnologia, contando com o conhecimento e com a compreensão dos estudantes, nativos digitais.

Nesse desenho, a adaptação de um Projeto de Aprendizagem - PA -, como material didático de apoio para o desenvolvimento das práticas discentes em plena era digital, é relevante e pertinente, pois se cogita interação e troca de saberes e experiências entre os sujeitos envolvidos neste processo: professores e estudantes. Além do mais, Fagundes et al (1999), argumentam que utilizar os PAs é acreditar em uma concepção de aprendizagem distinta da presente na maioria das escolas tradicionais que são calcadas no ensino clássico, isto é, uma forma de modicar os processos de ensino e aprendizagem por meio das atividades docentes.

Assim, o presente artigo tem o intuito de relatar uma experiência no cerne de uma metodologia diversificada com o uso das TICs no viés da adaptação da metodologia de Projetos de Aprendizagem na disciplina de Seminário Integrado, cobiçando a associação de saberes científicos e tecnológicos entre professor e estudante de modo a instigar o educando a promover debates éticos, concisos e fundamentados epistemologicamente na temática, fornecendo-lhes subsídios teóricopráticos no arquitetamento dos projetos científicos, de modo individual ou coletivo.

\section{Referencial teórico}

A reestruturação curricular no Ensino Médio gaúcho trouxe em suas vertentes uma disciplina caracterizada como Seminário Integrado, a qual se constitui na relação entre o currículo da parte geral e da parte diversificada, isto é, uma disciplina que compõe a necessidade dos professores instigarem os estudantes a desenvolverem projetos de pesquisa que estão, intrinsicamente, relacionando as áreas do conhecimento e o contexto sociocultural.

A articulação dos dois blocos do currículo, por meio de projetos construídos nos seminários integrados, se dará pela interlocução entre as áreas de conhecimento e os eixos transversais (instituídos pelos Parâmetros Curriculares Nacionais), oportunizando apropriação e possibilidades do mundo do trabalho (SEDUC, 2011, p. 23).

Quanto a parte de formação geral do currículo, entende-se, segundo os documentos da Seduc (2011, p. 23) que se compõe em "um trabalho interdisciplinar com as áreas de conhecimento com o objetivo de articular o conhecimento universal sistematizado e contextualizado com as novas tecnologias, com vistas à apropriação e integração com o mundo do trabalho". Já, sobre a parte diversificada, onde se relaciona 
especificamente a disciplina supracitada com vertentes humana, politécnica e tecnológica, prevê-se "a articulação das áreas do conhecimento, a partir de experiências e vivências, com o mundo do trabalho, a qual apresente opções e possibilidades para posterior formação profissional nos diversos setores da economia e do mundo do trabalho" (SEDUC, 2011, p. 23).

Neste viés, a disciplina de Seminário Integrado nasce como "espaços planejados, integrados por professores e alunos, a serem realizados desde o primeiro ano e em complexidade crescente. Organizam o planejamento, a execução e a avaliação de todo o projeto político-pedagógico, de forma coletiva, incentivando a cooperação, a solidariedade e o protagonismo do jovem adulto" (SEDUC, 2011, p. 23).

Desta forma, percebe-se a necessidade de se desenvolver atividades diferenciadas, utilizandose materiais de apoio de forma tecnológica, a fim de garantir múltiplos saberes discentes, pois estes saberes são constituídos tanto pelas referências particulares de cada educando (contexto sociocultural e sócio-histórico), como pelos processos de ensino e de aprendizagem vividos na escola.

Neste desenho, o entendimento dos saberes discentes, por parte dos professores, deve possibilitar uma reavaliação das próprias práticas metodológicas, visando o atendimento das necessidades e interesses dos próprios estudantes. Assim, tem-se uma metodologia docente que aborda parte de uma perspectiva pedagógica, percebendo os alunos e professores como sujeitos ativos e influentes no processos de ensino e de aprendizagem.

Diante desta perspectiva, o professor acaba atuando como mediador da apropriação do conhecimento, proporcionando aos estudantes a visão de que os mesmos são agentes ativos do próprio saber; responsáveis pelo processo de aprendizagem e qualificadores das ações docentes.

Assim, percebe-se que a metodologia de PAs é um mecanismo de qualificação para fazer com que o educando se envolva de forma ativa e hábil neste processo, uma vez que, segundo Carvalho $e t$ al (2007), o "estudante torna-se produtor de conhecimento, abrem-se possibilidades dele se integrar a uma rede de autores, ao invés de um mero consumidor" (p. 43).

Entretanto, entende-se que adotar os PAs como uma nova forma de acreditar na aprendizagem autônoma requer primeiramente a responsabilidade de adaptar-se e estar aberto ao novo, entendendo o processo como lento e muito flexível. Portanto, existe a necessidade de ações sobre avaliação e reflexão constantes na nova metodologia, pois a transformação, ao mesmo tempo em que provoca, convoca todos a repensar a educação e a forma como se organiza, e isso requer comprometimento, dedicação e empenho.

Nesta teia, outros dois princípios fundamentais que se justapõem a esta metodologia, tanto ao professor quanto ao estudante, são a pesquisa e a sistematização do pensamento, que utilizando-se de recursos tecnológicos disponíveis ao contexto em que é vivenciado, consentem a ação e reflexão diante das descobertas e experiências vivenciadas (CARVALHO et al, 2007).

Portanto, tem-se que a atividade docente, quando conectada à proposta da metodologia dos PAs pode possibilitar aos sujeitos uma vivência autônoma e dialógica de construção de conhecimento, oportunizando aos sujeitos uma prática coerente com o contexto do educando e o conhecimento científico do professor, assim como uma ação de aprender a aprender questionar, pesquisar, decodificar e socializar conhecimentos.

Destarte, entende-se a metodologia de PAs associada a atividades de qualificação e enriquecimento dos processos de ensino e de aprendizagem como prática que prevê a própria transformação explorada em sala de aula. Precisamente, Fagundes et al (1999), refere-se às Tecnologias da Informação e da Comunicação, vistas como uma possibilidade de socialização; um aspecto primordial na construção do conhecimento e na proliferação da informação.

Em contrapartida, Fagundes et al (1999), ressalvam que "buscar a informação em si, não basta. É apenas parte do processo para desenvolver um aspecto dos talentos necessários ao cidadão. Os alunos precisam estabelecer relações entre as informações e gerar conhecimento. Não há interesse em registrar se o aluno retém ou não uma informação, aplicando um teste ou uma "prova" objetiva, por exemplo; porque isso não mostra se ele desenvolveu um talento ou se construiu um conhecimento que não 
possuía. O que interessa são as operações que o aprendiz possa realizar com estas informações, as coordenações, as inferências possíveis, os argumentos, as demonstrações. Pois, para construir conhecimento, é preciso reestruturar as significações anteriores, produzindo boas diferenciações e integrando ao sistema as novas significações. Esta integração é resultado da atividade de diferentes sistemas lógicos do sujeito, que interagem entre si e com os objetos a assimilar ou com os problemas a resolver. Finalmente, o conhecimento novo é produto de atividade intencional, interatividade cognitiva, interação entre os parceiros pensantes, trocas afetivas, investimento de interesse e valores" (FAGUNDES et al, 1999, p. 24).

Assim, percebe-se que a metodologia de PAs faz com que o professor passe a assumir um papel de instigador da inteligência coletiva dos grupos de pesquisas com os quais está interagindo, centrando sua atividade no acompanhamento e na gestão das aprendizagens. No mesmo desenho, este professor passa a ser problematizador e desafiador sobre os projetos de pesquisa desenvolvidos pelos estudantes, a fim de incitá-los à troca de saberes, desenvolvimento de competências e habilidades. Assim sendo, o que vai determinar a forma como os diferentes recursos e ferramentas tecnológicas serão utilizadas, "são os pressupostos epistemológicos presentes na prática do docente" (SCHLEMMER, 2001, p. 16).

Nesta perspectiva, é interessante desenvolver a metodologia supracitada com a utilização das TICs para a proliferação de informações que sustentam o desenvolvimento de atividades de pesquisa. Neste desenho, entende-se que as mudanças tecnológicas atuais impuseram novos ritmos, novas percepções e racionalidades múltiplas, de maneira que abrolharam novos comportamentos de aprendizagem. Se antes a tarefa de ensino-aprendizagem era exclusiva da escola, hoje são múltiplas as agências que possibilitam informações e conhecimentos (KENSKI, 1997; 2008).

Entretanto, é visível a resistência de muitos professores em relação ao uso das tecnologias dentro da sala de aula, a qual pode derivar em decorrência da descrença das contribuições da tecnologia aos processos de ensino e de aprendizagem e/ou do medo de que sua função seja superada. Todavia, as novas tecnologias não substituirão ou enfraquecerão a importância do professor, pois o que elas fazem é ampliar e intensificar as possibilidades cognitivas e interativas no processo de construção de conhecimentos, assumindo múltiplas formas e metodologias didáticas (ASSMANN, 2000).

Nesse sentido, entende-se que a metodologia de PAs torna-se um fator crítico para a integração da tecnologia no processo educativo, sendo necessário oferecer aos professores melhor compreensão e entendimento sobre determinada metodologia, além de um desenvolvimento prático e colaborativo-efetivo. Assim, tem-se que esse elo entre TICs e PAs é mecanismo para promover um adequado ensino, aumentando a possibilidade de uma ótima integração do professor e os estudantes na qualificação dos processos de ensino e de aprendizagem.

Fagundes et al (1999, p. 17) enfatizam que é fundamental entender que a aprendizagem resulta da interação operacional dos sujeitos que constroem o conhecimento enquanto agem e se comunicam com o seu meio, com outros indivíduos e com objetos do conhecimento científico, tecnológico, social, artístico, etc. dos quais eles desejam e necessitem se apropriar.

Portanto, o pressuposto da atividade com PAs impulsiona a possibilidade de um trabalho interdisciplinar, oportunizando o desenvolvimento do pensamento e da autonomia por meio de trocas que favorecem a tomada de consciência entre os sujeitos, além de favorecer o desenvolvimento de um processo dialético de construção do conhecimento, a fim de permitir ações que favoreçam a metodologia de aprender e ensinar por meio de atualizações cognitivas e pedagógicas.

Por fim, acredita-se que o acesso à tecnologia e a metodologias didáticas que favoreçam a construção da aprendizagem de forma autônoma e dialógica pode, de certa forma, contribuir significativamente para que o professor se sinta mais preparado e capacitado para o uso didático das tecnologias e o educando para a construção da própria aprendizagem. Desta forma, proporciona-se, aos estudantes que vivenciam durante seus processos de formação momentos em que podem fazer uso pedagógico das tecnologias, maiores ocasiões de compreender e utilizar as tecnologias em prol da construção, contextualização e socialização do saber. 
Não obstante, acredita-se que o viés existente entre TICs e a metodologia de PAs, de certa forma, auxilia no desenvolvimento de competências e habilidades necessárias para que o educando, de forma contemporânea, possua conhecimentos e habilidades que lhe permitam interpretar e analisar, de maneira crítica e autônoma, a crescente quantidade de informações virtuais.

\section{Metodologia}

O desígnio da atividade estar entrelaçada à temática Sustentabilidade Ambiental, tema gerador do segundo ano do Ensino Médio Politécnico de uma escola pública do norte do estado gaúcho, adveio de uma pesquisa sócioantropológica aplicada e interpretada na/pela mesma escola. Tal tema deriva de uma pesquisa realizada no início do ano de 2013, quando a direção da escola distribuiu um questionário sócio-antropológico para os estudantes, a fim de cogitar o surgimento de um tema norteador para as atividades docentes.

Frente a isto, tem-se nos documentos normativos da politecnia que o "currículo deverá considerar os significados socioculturais de cada prática, no conjunto das condições de existência em que ocorrem; esta dimensão fornece os sistemas simbólicos que articulam as relações entre o sujeito que aprende e os objetos de aprendizagem" (SEDUC, 2011, p. 16).

Semanas depois, com os questionários em mãos, a direção, em uma reunião com professores e funcionários, analisou-os a fim de encontrar o eixo para nortear as atividades a serem desenvolvidas no decorrer do ano letivo. Tal análise deu início ao tema: Sustentabilidade Ambiental e, a partir de então, todos os trabalhos desenvolvidos no decorrer deste período tiveram como plano de fundo a temática supracitada.

A análise demonstra que a população do município sobrevive com o meio rural, pois o questionário apresentava questões que, de certa forma, instigava a sobrevivência e a relação familiar com o município. Assim, também, possibilita-se uma relação do contexto social, educacional e ambiental, favorecendo a construção e emancipação de valores frente a necessidade de preservação e convívio com o ambiente.
Diante da proposta sócio-antropológica e com o intuito de promover um ambiente diversificado para favorecer a construção de saberes nos processos de ensino e de aprendizagem na disciplina de Seminários Integrados, instigou-se 49 estudantes, desta modalidade de ensino e, especificamente, dos segundos anos, a procurarem em revistas e jornais - materiais disponibilizados pelo professor - imagens que, de certa forma, retratassem a temática Sustentabilidade Ambiental; imagens de diferentes contextos que, por sua vez não abrangessem linguagem teórica ou simbólica, que focassem no eixo norteador desta modalidade de ensino.

Neste viés, ao possibilitar uma articulação entre as imagens que retratam a Sustentabilidade Ambiental e a reflexão sobre a diversidade existente no contexto do educando de forma científica, desde seus afazeres, dizeres, símbolos e códigos, proporciona-se, também, condições de inter-relacionamento teórico-expositivo, pois quando se realiza a observação sobre um artefato, independentemente da forma, entende-se que nesta deixam-se emergir saberes e vozes que estão para além da própria confecção do pensamento, uma vez que atrelam conhecimentos de todas os materiais lidos, conhecidos e experimentados.

A adaptação sobre a metodologia de PAs teve durabilidade de duas horaslaula, mas, por se tratar de um trabalho que teve sua extensão na modalidade do Ensino Médio Politécnico, teve seu término durante o primeiro semestre do ano de 2013. A confecção do projeto final foi um marco primordial para os estudantes, uma vez que estavam diretamente conectados a um tema de interesse próprio e, além do mais, desenvolviam trabalhos coletivamente, visando o uso das tecnologias como meio de fragmentar a distância entre o saber e o aprender.

Por meio da utilização das TICs (computadores, celulares e câmeras fotográficas), assim como a adaptação sobre a metodologia de PAs, emergiu-se uma maneira de romper com tradicionalismo da transmissão de informação na disciplina de SI, auxiliando os sujeitos dos processos de ensino e de aprendizagem a saída do comodismo, pois, de acordo com Boutinet (2002), uma das razões que encorajam a pedagogia de projetos vem da necessidade de quebrar o quadro coercitivo dos programas escolares para suscitar certa criatividade (p. 180). Entretanto, cabe 
ressaltar que o fato acima citado demanda tempo, seriedade, disponibilidade, coerência e competências por parte dos sujeitos envolvidos, tanto professores quanto estudantes.

\section{Resultados e discussões}

A atividade foi descrita em um plano de aula e teve sua aplicabilidade como princípio de reformulação da prática docente, favorecendo a qualificação dos saberes discentes e dos processos de ensino e de aprendizagem frente Sustentabilidade Ambiental à luz da utilização das tecnologias e adaptação da metodologia dos PAs na confecção de projetos de pesquisa.

Para melhor abrangência e compreensão da atividade e dos resultados nela contidos, optou-se em apresentar detalhadamente $\mathrm{o}$ desenvolvimento do ambiente de aprendizagem, de forma a contextualizá-lo com autores que fundamentam o uso das TICs e os PAs como foco primordial na construção e reconstrução de saberes discentes.

Ao tocante, serão apresentados os eixos que foram levantados pelos estudantes para a confecção do projeto científico e seus derivados objetivos, a fim de relacionar a temática nos contextos social, cultural e institucional do educando.

\subsection{Desenho da pesquisa}

Para cada estudante, em ambas as turmas, entregou-se uma revista e diversos jornais, além de possibilitar a ação de registro de imagens por meio de foto e pesquisas via celular ou computador, a fim de que os mesmos coletassem uma imagem que representasse interesses de pesquisa focados na Sustentabilidade Ambiental. Em seguida, solicitou-se aos estudantes para que realizassem, em forma teórica no caderno, uma análise crítico-reflexivo sobre a imagem coletada, podendo, neste momento, acessar a Internet via uso do celular para encontrar textos escritos por autores que pudessem, de certa forma, enriquecer suas concepções e percepções acerca do determinado tema.

Observando-se a figura abaixo (Figura 1), pode-se perceber o número de imagens sobre as temáticas semelhantes que emergiram na realização desta atividade entre os estudantes.

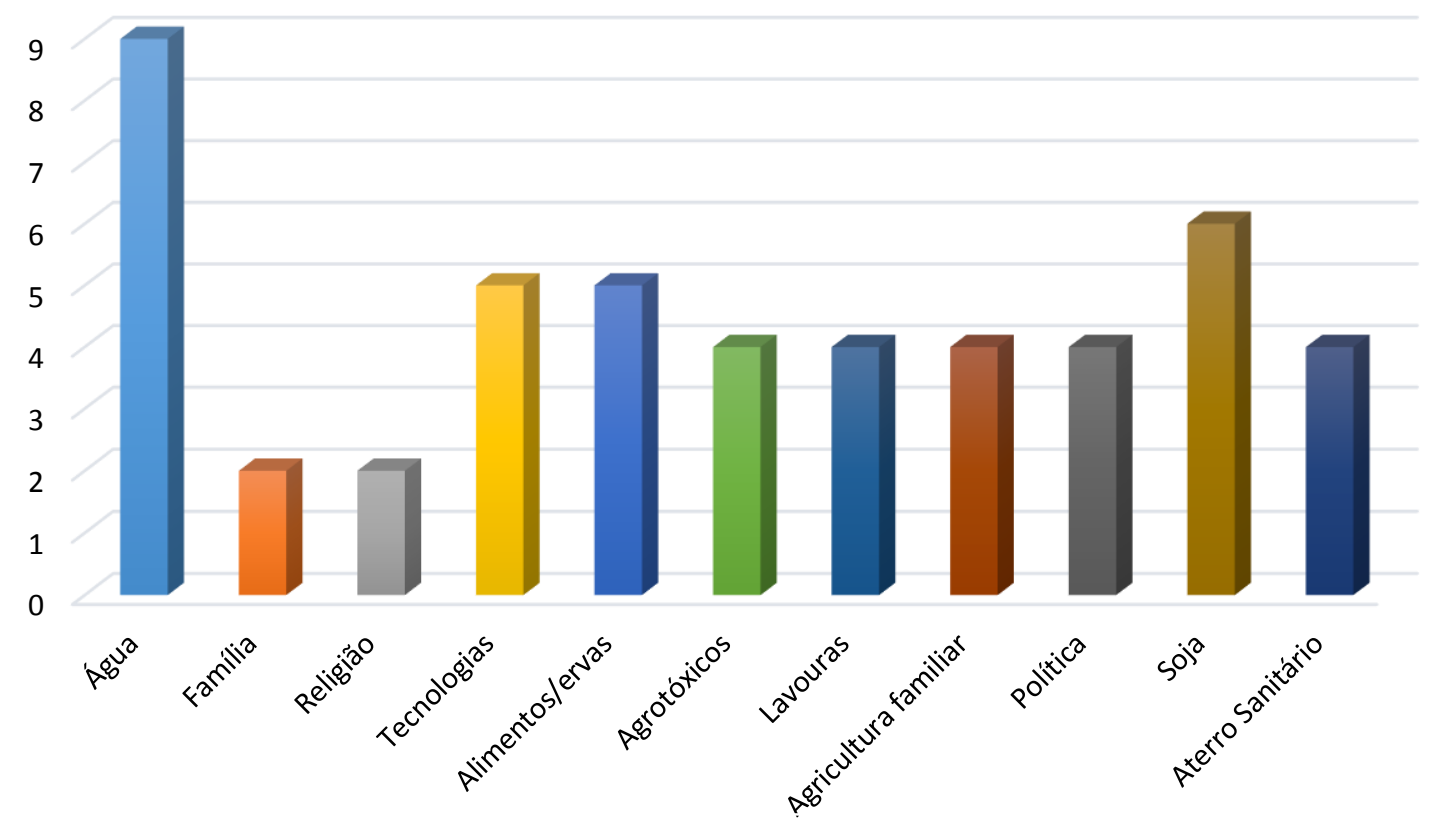

Figura 1: Número de imagens por tema abordado.

Fonte: Trabalho desenvolvido na aula de Seminário Integrado. Primeiro semestre de 2013. Org. BEDIN; DEL PINO (2015).

Em seguida, instigou-se aos estudantes para que socializassem suas observações oralmente e, posteriormente, que se reunissem por afinidade de assuntos. Esta afinidade por assunto fez surgir os grupos de pesquisa entre os estudantes, os quais desenvolveram os projetos de pesquisa. Percebe-se, nesta ação docente, que os estudantes se reuniram por semelhança de interesse, não por coleguismo ou amizade, como, normalmente, 
ocorre dentro da sala de aula na realização de atividades em grupo.

Posteriormente a formação dos grupos, os estudantes, com o auxílio do professor, delimitaram o tema de pesquisa abrangente sobre a imagem. Na organização do grupo para a elaboração do projeto de pesquisa, os estudantes definiram, mediante explicação do professor, o problema a ser investigado e o objetivo a ser alcançado, em seguida, começaram a desenvolver um projeto científico com a inserção das TICs (computador, celular, câmera digital) no viés da Sustentabilidade Ambiental.

Assim, compreende-se que não basta apenas transmitir informação, mas é "fundamental saber transformar informações em conhecimento próprio através de procedimentos adequados de aprendizagem. Que a aprendizagem virtual vai se impor e dominar o cenário futuro, não há escapatória. Cumpre, pois, também à escola educar as novas gerações para usar bem a nova mídia" (DEMO, 2007, p. 91).

Segundo Fagundes et al (1999), a aprendizagem resulta da interação operacional dos sujeitos que constroem o conhecimento enquanto agem, comunicam-se e interagem com seu meio, com a matéria do conhecimento científico, tecnológico, social e artístico, etc. dos quais desejam e precisam se apoiar para o desenvolvimento integral do conhecimento.

Analisando-se a atividade docente, percebe-se que a adaptação da metodologia de PAs, metodologia que concentra-se nos pressupostos da atividade cooperativa, envolvendo diversos espaços de interação, além de possibilitar um processo de ação-reflexão continuado dos sujeitos da aprendizagem, foi uma atividade diferenciada e qualificada aos processos de ensino e aprendizagem. Este pressuposto de atividade cooperativa anexa e impulsiona a possibilidade de um trabalho interdisciplinar, pois oportuniza o desenvolvimento do pensamento e da autonomia por meio de trocas intelectuais, sociais, culturais e políticas.

Quando o aprendiz é desafiado a questionar, quando ele se perturba e necessita pensar para expressar suas dúvidas, quando lhe é permitido formular questões que tenham significação para ele, emergindo de sua história de vida, de seus interesses, seus valores e condições pessoais, passa a desenvolver a competência para formular e equacionar problemas. Quem consegue formular com clareza um problema, a ser resolvido, começa a aprender a definir as direções de sua atividade (FAGUNDES et al, 1999, p. 16).

Assim, tem-se que essa metodologia implica um projeto comunicacional descentrado, porém mediado, em praticamente todas as funções interativas possíveis no espaço do ambiente e, em se tratando da disciplina de Seminário Integrado, percebe-se a necessidade da relação com as outras áreas de conhecimento, favorecendo o viés interdisciplinar.

A construção de um projeto científico é o norte desta nova modalidade de ensino, portanto, além de se oportunizar condições de saberes críticosreflexivos sobre o meio ambiente, o trabalho desenvolvido na turma do segundo ano também possibilitou aos estudantes adquirirem saberes referentes à construção de um projeto científico, a delimitação de um tema e a escolha de uma problemática, pois, segundo Fagundes et al (1999, p. 24), a metodologia de Projetos de Aprendizagem favorece a prática pedagógica cooperativa, que se dá por trocas recíprocas e respeito mútuo, já que o professor desempenha o papel de mediador, desvalorizando o papel de dono do saber.

A adaptação desta metodologia é importante e relevante na educação básica e na confecção de projetos de pesquisa, pois quem escolhe o tema a ser investigado são os estudantes e os professores, nascendo dos conflitos, das perturbações, da realidade e do contexto dos sujeitos envolvidos. Entretanto, destaca-se que foi feito, pelo professor da disciplina, uma adaptação, já que os temas a serem selecionados por meio das imagens deveriam, de certa forma, estarem vinculados as questões ambientais.

Assim, os temas que os estudantes, na análise crítico-reflexivo, propuseram para aprofundar o conhecimento e desenvolver os projetos de pesquisa na matriz dos PAs, entendidos por Hernández (1998) como "Projetos de Trabalho", pois se acredita que todos os envolvidos neste processo instigam uma interação interpessoal, uma vez que se constrói um conjunto de ações diversificadas que permitem a participação ativa do estudante como coautor de sua formação sociocultural, são, em ordem aleatória, apresentados com seus escoltados objetivos na figura 2 a seguir. 


\begin{tabular}{|c|c|}
\hline Grupo & Objetivo Geral \\
\hline A & $\begin{array}{l}\text { Estudar, refletir e construir um reservatório de água, a fim de demonstrar como a água } \\
\text { poluída pode ser reutilizada por meio da ação do aguapé, levando em consideração a } \\
\text { necessidade da água potável. }\end{array}$ \\
\hline B & $\begin{array}{l}\text { Entender como e de que forma os valores familiares, quando passados de pais para filhos, } \\
\text { influenciam na sustentabilidade ambiental pós modernização. }\end{array}$ \\
\hline C & $\begin{array}{l}\text { Entender e refletir de que maneira uma crença religiosa faz emergir o bem estar nas pessoas, } \\
\text { a fim de torná-las mais conscientes em relação a valorização do meio ambiente. }\end{array}$ \\
\hline D & $\begin{array}{l}\text { Entender como as pessoas, por meio das redes sociais, promovem o debate sobre } \\
\text { sustentabilidade ambiental e defendem seus argumentos sobre a temática. }\end{array}$ \\
\hline E & $\begin{array}{l}\text { Descobrir e entender como e quais são os alimentos e ervas medicinais que influenciam na } \\
\text { prevenção de doenças cancerígenas. }\end{array}$ \\
\hline $\mathbf{F}$ & $\begin{array}{l}\text { Investigar e apresentar a importância da ação sobre a reciclagem das embalagens de } \\
\text { agrotóxicos, auxiliando na descontaminação do solo e preservação do meio ambiente. }\end{array}$ \\
\hline G & $\begin{array}{l}\text { Avaliar as diferentes formas de produção dos tubérculos de batata no município de } \\
\text { Ibiraiaras, a fim de averiguar o melhor método para assegurar qualidade no ambiente. }\end{array}$ \\
\hline $\mathrm{H}$ & $\begin{array}{l}\text { Entender e refletir sobre o Êxodo Rural em Ibiraiaras, destacando os motivos para o mesmo } \\
\text { emergir. }\end{array}$ \\
\hline I & $\begin{array}{l}\text { Apresentar subsídios teóricos e práticos para a recuperação e despoluição da água do } \\
\text { Arroio Mormaço, contando com a ajuda das políticas públicas e da populaça municipal. }\end{array}$ \\
\hline $\mathbf{J}$ & $\begin{array}{l}\text { Mostrar a melhor forma de produzir soja sem causar danos a natureza, enfatizando no } \\
\text { melhor modo de utilizar a terra e o manuseio adequado dos pesticidas para o controle de } \\
\text { pragas e doenças que afetam a lavoura. }\end{array}$ \\
\hline K & $\begin{array}{l}\text { Entender, refletir e demonstrar a importância de um aterro sanitário em um determinado } \\
\text { município como meio de maximização das ações ambientais. }\end{array}$ \\
\hline
\end{tabular}

Figura 2: Representações dos objetivos que os grupos almejaram referente a Sustentabilidade Ambiental no contexto dos PAs. Fonte: Trabalho desenvolvido na aula de Seminário Integrado. Primeiro semestre de 2013. Org. BEDIN; DEL PINO (2015).

Para melhor entendimento da figura 2 acima, plotou-se uma figura 3 que apresenta porcentagem de alunos por projetos responsáveis por cada projeto. Observe a figura 3 na sequência.

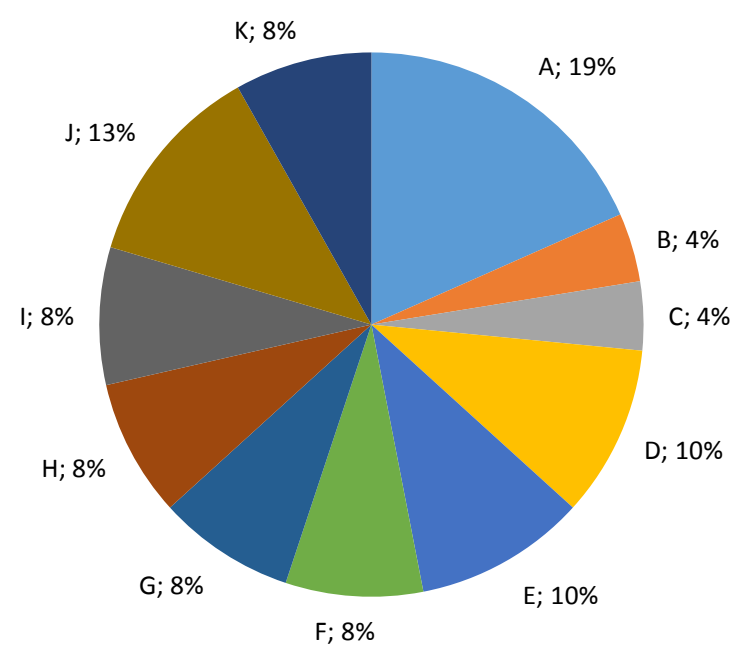

Figura 3: Representação em percentagem de estudantes por Projetos de Pesquisa

Fonte: Trabalho desenvolvido na aula de Seminário Integrado. Primeiro semestre de 2013.

Org. BEDIN; DEL PINO (2015).
Analisando as figuras 2 e 3 acima apresentadas, pode-se pensar que todos os estudantes conseguem, de certa forma, encaixar seus objetivos de interesse ao tema Sustentabilidade Ambiental. Em uma ótica superficial, temas de religiosidade e valores pessoais seriam os que, grosso modo, os estudantes mostrariam dificuldades em encaixar à temática, mas, com o apoio do professor e com os demais colegas, os estudantes conseguiram agrupá-los de forma assíncrona e sistêmica.

Nesse sentido, Piaget (2001) refere à assimilação e à acomodação nas relações com a afetividade quando assinala que não há trabalho sem necessidade; não há ato de inteligência sem pergunta, quer dizer, sem experimentar a sensação de uma lacuna, portanto, sem desequilíbrio, sem necessidade. Maturana e Zöller (2004), neste mesmo perfil, mencionam que a base da rede de conversação é o emocionar presente nesta, e Piaget (2001) ensina que, a partir da relação de afetividade, é que surge a necessidade de estudo. “A noção de equilíbrio 
tem uma significação fundamental, tanto do ponto de vista afetivo como intelectual" (PIAGET, 2001, p. 20). Em outras palavras, os estudantes buscaram imagens que refletiam, naquele momento, o que sentiam e vivenciavam sobre Sustentabilidade Ambiental, deixando-se levar pela cultura, pelos valores e pela própria história de vida

Diante dos fatos, percebe-se que os estudantes, conseguem, com o avanço da Internet e com a qualificação da Web 2.0, integrar seus estudos nos mais diferentes meios e com diversificada amplitude, pois o uso dos celulares, assim como dos computadores, se tornou um dos mais sofisticados modos de trabalhar dentro da sala de aula.

Neste viés, os sujeitos que interagem no mundo se constituem autores do próprio saber, pois realizam pesquisas de opinião, buscas virtuais, acessam a Internet com facilidade e cogitam a mescla dos saberes, a fim de usufruir de uma forma diferenciada de interagir com a máquina e construir conhecimento.

Quando se pensa no uso das TICs, especificamente na metodologia de PAs, deve-se considerar o uso das mesmas para atrofiar $\mathrm{o}$ distanciamento entre os saberes científicos e os saberes do senso comum, a fim de enriquecer e inovar as práticas pedagógicas, pois estas são recursos facilitadores para a ação docente. Para tanto, a mescla com esses materiais tecnológicos exige do profissional da educação competências, habilidades e criatividade para buscar a organização do saber coletivamente, de forma a possibilitar ao educando aprender a aprender.

Por outro lado, a aliança entre o contexto tecnológico e o processo de ensino/aprendizagem acaba colocando uma série de problemas. Assim, as novas tecnologias devem ser introduzidas no currículo de maneira adequada e não por uma simples eleição. O professor deve perceber que tais tecnologias funcionam, antes de usá-las efetivamente para trabalhar com seus alunos. Então, como educadores, temos o dever de apurar a massa de tecnologias para fazer uma seleção de recursos que estejam adequados aos nossos propósitos educacionais (GROSSECK; MARINHO; TÁRCIA; 2009, p. 117).

Neste exposto, é interessante pensar que a utilização das TICs no viés da sala de aula é uma forma de fornecer ao alunado e, ao mesmo tempo, ao professorado, uma diversificada forma de entender o conteúdo por meio do entretenimento seja via plataformas de comunicação, sites, blogs, e-mails e, dentre outras formas, redes sociais.

Assim, tem-se conhecimento da necessidade de questionar e refletir sobre a Sustentabilidade Ambiental dentro da sala de aula seja por meio de leituras, desenhos, mesas redondas, debates ou construção de projetos científicos, pois, de acordo com a Política Nacional de Educação Ambiental (Brasil, 1999, art. 1º): entende-se por educação ambiental os processos por meio dos quais o indivíduo e a coletividade constroem valores sociais, conhecimentos, habilidades, atitudes e competências voltadas para a conservação do meio ambiente, bem de uso comum do povo, essencial à sadia qualidade de vida e sua sustentabilidade.

Considerando-se a importância de um meio ambiente no reflexo do desenvolvimento humano, almejando-se o uso excessivo dos produtos que estão vinculados a disposição na mídia, o consumo desenfreado movido pela curiosidade e os processos de rapidez no descarte dos materiais inutilizáveis, entra em conflito a ação docente de promover, por meio de diversas formas, a conscientização e o desenvolvimento do espírito crítico dos estudantes com as propagandas ilusórias que, por meio de imagens e sons, induzem os estudantes ao consumismo indisciplinado.

Assim, a ideia de sustentabilidade implica a prevalência da premissa de que é preciso definir uma limitação nas possibilidades de crescimento e um conjunto de iniciativas que levem em conta a existência de interlocutores e participantes sociais relevantes e ativos através de práticas educativas e de um processo de diálogo informado, o que reforça um sentimento de coresponsabilização e de constituição de valores éticos. Isso também implica que uma política de desenvolvimento na direção de uma sociedade sustentável não pode ignorar nem as dimensões culturais nem as relações de poder existentes e muito menos o reconhecimento das limitações ecológicas, sob pena de apenas manter um padrão predatório de desenvolvimento (JACOBI, 1999. p. 179).

Neste meio, tem-se o conhecimento pedagógico acerca da importância da temática ser debatida e refletida pela ação discente por meio da construção de projetos científicos à luz da adaptação da metodologia dos PAs, os quais 
visam à compreensão dos recursos naturais como fontes de desenvolvimento humano no intercâmbio da ação interpessoal, pois Fagundes et al (1999) argumentam que utilizar os PAs é entender concepções de aprendizagem distintas das presentes na maioria das escolas que são calcadas no ensino tradicional.

Portanto, é riquíssimo trabalhar com a metodologia dos PAs, já que, nesta metodologia, os estudantes se tornam autores do próprio saber, pois, individualmente ou coletivamente, eles levantam um tema a ser pesquisado, seja por meio da curiosidade ou do desejo de aprender, sobre determinado assunto. O papel de problematizar um determinado assunto cabe ao professor que, mediante habilidades e competências, desafia e instiga o educando a ser o agente central dos processos de ensino e de aprendizagem.

Esta perspectiva, se concretiza na proposta de PAs, pois "é essencial que a curiosidade do aluno, suas dúvidas, suas questões decidam o assunto a ser pesquisado pois neste caso os conteúdos não serão impostos pelo professor, mas buscados pelo estudante, pois a motivação para aprender é intrínseca ao indivíduo, depende de seu desejo de conhecer, de sua necessidade de saber" (FAGUNDES et al, 2005b, p. 45).

Nesta questão, Fagundes et al (2005) definem claramente a diferença entre Projetos de Aprendizagem e de Ensino, pois em um Projeto de Ensino quem decide o que será investigado são os professores; a decisão costuma visar o currículo e não os interesses dos alunos. Segundo Fagundes (2005a) no ensino por projetos, "tudo parte das decisões do professor, e a ele, ao seu controle, deverá retornar. Como se o professor pudesse dispor de um conhecimento único e verdadeiro para ser transmitido ao estudante e só a ele coubesse decidir o que, como e com que qualidade deverá ser aprendido. Não se dá oportunidade ao aluno para qualquer escolha. Não lhe cabe tomar decisões. Espera-se sua total submissão a regras impostas" (FAGUNDES et al, 2005a, p. 15).

Para melhor compreensão sobre as diferenças entre esses dois tipos de projetos, plotou-se uma figura estruturada por Fagundes (2005a). Observe a figura 4 a seguir:

\begin{tabular}{|c|c|c|}
\hline & Ensino por projetos & Aprendizagem por projetos \\
\hline Quem escolhe o tema & $\begin{array}{l}\text { Professores, coordenação } \\
\text { pedagógica }\end{array}$ & $\begin{array}{l}\text { Alunos e professores individualmente e, } \\
\text { ao mesmo, tempo, em cooperação }\end{array}$ \\
\hline Contextos & $\begin{array}{l}\text { Arbitrado por critérios } \\
\text { extremos e formais }\end{array}$ & Realidade da vida do aluno \\
\hline A quem satisfaz? & $\begin{array}{l}\text { Arbítrio da sequência dos } \\
\text { conteúdos do currículo }\end{array}$ & $\begin{array}{l}\text { Curiosidade, desejo, vontade do } \\
\text { aprendiz }\end{array}$ \\
\hline Decisões & Hierárquicas & Heterárquicas \\
\hline $\begin{array}{l}\text { Definições de regras, } \\
\text { direções e atividades }\end{array}$ & $\begin{array}{l}\text { Impostos pelo sistema, } \\
\text { cumpre determinações sem } \\
\text { optar }\end{array}$ & $\begin{array}{l}\text { Elaboradas pelo grupo, consenso de } \\
\text { alunos e professores }\end{array}$ \\
\hline Paradigma & Transmissão do conhecimento & Construção do conhecimento \\
\hline Papel do professor & Agente & Estimulador/orientador \\
\hline Papel do aluno & Receptivo & Agente \\
\hline
\end{tabular}

Figura 4: Ensino por Projetos X Aprendizagem por Projetos.

Fonte: Fagundes et al. (2005a, p. 17)

Org. BEDIN; DEL PINO, 2015

Destarte, percebe-se que trabalhar o tema Sustentabilidade Ambiental no viés dos PAs foi uma forma de aproximar o professor e os estudantes, pois o tema foi desenvolvido em conjunto, gerado pelos conflitos e pelas perturbações dos envolvidos num determinado contexto, em seu ambiente de vida e pelas concepções e ideias que carregavam acerca da temática no viés das imagens.

Do mesmo modo, o assunto desenvolvido nos projetos de pesquisas à luz da metodologia de PAs e da temática estabelecida com o auxílio das TICs deriva da necessidade e da curiosidade dos estudantes, uma vez que a motivação é intrínseca, 
própria do sujeito que aprende e, para Schlemmer (2001), as decisões são heterárquicas e não impostas pelo professor (p. 07).

Por fim, entende-se que a adaptabilidade da metodologia dos PAs favoreceu a cooperação do alunado, a busca incansável do conhecimento crítico para aprofundar concepções e trocar

\section{Conclusões}

Este artigo buscou apresentar algumas reflexões sobre a utilização das Tecnologias da Informação e Comunicação em um ambiente de aprendizagem da disciplina Seminário Integrado que visava, como plano de fundo, a confecção de um projeto científico à luz da Sustentabilidade Ambiental, além de apresentar aos educandos a metodologia de PAs e a observação crítica frente a imagens.

Desta forma, por meio das finalidades nos processos de ensino e de aprendizagem e por meio de práticas sociais e educacionais, pretendeu-se, com o trabalho desenvolvido, valorizar o contexto de aprendizagem na era digital frente à temática ambiental, garantindo a proliferação das informações, a aquisição de saberes e a ressignificação de conceitos e percepções discentes.

A opção pelo artigo estar pautado à adaptação da metodologia de PAs, advém da necessidade de aquisição de conhecimento e informação por parte do corpo docente para que se possa desenvolver um trabalho qualificado junto aos estudantes, atribuindo-lhes significados àquilo que aprendem sobre questões de cunho científico, utilizando-os como instrumentos metodológicos e tecnológicos de apoio docente para capacitar melhor às novas gerações.

O impacto da utilização da metodologia de PAs, por meio da reflexão crítica das imagens, a fim de construir um projeto científico na ótica da temática, por deveras se considerou positivo, pertinente e instigante, visto que se criou uma expectativa a mais para as aulas de Seminário Integrado, incentivando o interesse nos estudantes e possibilitando a estes o exercício de compreensão da tecnologia por meio da prática diária, observando-a não somente como mero objeto de lazer, mas também como instrumento de estudo e de construção de conhecimentos. experiências de forma recíproca e respeitosa. Também, ressalva-se a ideia de que por meio desta metodologia os sujeitos envolvidos desenvolvem a capacidade de aprender e se constituir em um contexto coletivo, autônomo e crítico.

Nesse desenho, professor e estudante aprendem interagindo e assessorando um ao outro as formas de forjar e desenvolver um projeto científico na base das tecnologias sofisticadas da era digital, uma vez que a construção de um Projeto de Pesquisa é relevante e pertinente na medida em que existe interação e troca de saberes e experiências, pois o professor, com o passar do tempo, torna-se aprendiz na medida em que ensina.

Destaca-se, também, que a atividade desenvolvida com a adaptação da metodologia de PAs e a inserção das TICs, possibilitou a inclusão de colegas que eram excluídos na sala de aula, que foi observada e validada a partir do interesse de pesquisa. A proposta de escolher, escrever e conversar com os colegas de aula de uma maneira diferente fez com que os estudantes pudessem trabalhar com colegas "desconhecidos". Assim, percebe-se que a necessidade de trabalhar em grupo, colocando o interesse de pesquisa e não o coleguismo como norteador desta formação, é um passo importante para a cooperação e a transformação na convivência emergente na sala de aula.

Desta forma, percebe-se que é condição necessária para a constituição de um convívio cooperativo, interativo e dialógico, visando a aceitação e a ideia do outro, a fim de operacionalizar um processo de descentração cognitiva e afetiva. Na experiência, pode-se perceber que a partir da adaptação dos PAs e de recursos das Tecnologias Digitais foi possível instaurar uma modificação no domínio de ação dentro da sala de aula e nas práticas do professor, perturbando as dinâmicas normativas e enraizadas na escola.

Portanto, percebeu-se que, no final do ambiente de aprendizagem, com momentos de reflexão e socialização dos estudantes sobre a temática Sustentabilidade Ambiental, os mesmos alcançaram as expectativas específicas propostas no planejamento e confeccionaram projetos de pesquisa à luz da adaptação da metodologia de 
PAs com o apoio de materiais didáticos tecnológicos, sobre temas do próprio interesse; foram autores da própria construção do conhecimento e construíram a aprendizagem individual e coletiva no viés das imagens selecionadas, desfrutando das tecnologias para encontraram a excelência de aprender em meio ao entretenimento crítico-reflexivo.

\section{Referências}

ASSMANN, H. A metamorfose do aprender na sociedade da informação. Ciência da Informação, v. 29, n. 2. p. 7-15, 2000.

BOUTINET, J. P. Antropologia do Projeto. Porto Alegre: Artmed, 2002.

BRASIL. Ministério da Educação, Secretaria de Educação Média e Tecnologia. Parâmetros Curriculares Nacionais: ensino médio, Ministério da Educação, Brasília, 1999.

CARVALHO, M. J. S.; NEVADO, R. A. de; MENEZES, Crediné Silva de. Arquiteturas pedagógicas para educação à distância. Porto Alegre, Ricardo Lenz, 2007.

DEMO, P. O porvir: desafios da linguagem do século XXI. Curitiba, PR: Ibpex, 2007.

FAGUNDES, L. da C.; SATO, L. S. MAÇADA, D. L. Aprendizes do Futuro: as inovações começaram! Coleção Informática para a mudança na Educação. Brasília, MEC, 1999. Disponível em: $<\mathrm{http}$ ///www.dominiopublico.gov.br/download/t exto/me003153.pdf> Acesso em: 20 de jan de 2015.

FAGUNDES, L. da C.; et al. Aprendizes do Futuro: as inovações começaram! Disponível em $<$ http://mathematikos.psico.ufrgs.br/textos.html > . Acesso em: 23 out. 2005a.

FAGUNDES, L. da C.; et al. Programa Escola Conectividade e Sociedade da Informação e do Conhecimento. Disponível em $<$ http://ecsic.lec.ufrgs.br/>. Acesso em: 23 jan. 2005b.

GROSSECK, G.; MARINHO, S. P. P.; TÁRCIA, L. Educação a distância baseada na Web 2.0: a emergência de uma Pedagogia 2.0. EDUCAÇÃO \& LINGUAGEM. V. 12. N. 19. 111-123, JAN.-JUN. 2009
HERNÁNDEZ, F. Transgressão e Mudança na Educação: os projetos. Tradução de Jussara Haubert Rodrigues. Porto Alegre: Artmed: 1998.

JACOBI, P. Meio Ambiente e Sustentabilidade. In: Fundação Prefeito Faria Lima - Cepam. O município no século XXI: cenários e perspectivas. ed. Especial. São Paulo, 1999. 400 p.

KENSKI, V. M. Novas tecnologias: o redimensionamento do espaço e do tempo e os impactos no trabalho docente. Revista Brasileira de Educação, no ${ }^{07}$. Associação Nacional de PósGraduação e Pesquisa em Educação. Jan.-abr., 1997.

KENSKI, V. M. Tecnologias e ensino presencial e a distância. São Paulo: Papirus, 2008

MATURANA, H.; ZÖLLER, G. V. Amar e brincar: fundamentos esquecidos do humano. São Paulo: Palas Athena, 2004

PIAGET, J. Inteligencia y afectividad. Buenos Aires: Aique, 2001

SCHLEMMER, E. Projetos de Aprendizagem Baseados em Problemas: uma metodologia interacionista/construtivista para formação de comunidades em Ambientes Virtuais de Aprendizagem. Revista Digital da CVA RICESU. Colabora, Curitiba, v.1, n.2 - p. 10-21, novembro 2001.

SEDUCRS. Proposta Pedagógica Para o Ensino Médio Politécnico e Educação Profissional Integrada ao Ensino Médio - 2011-2014. Disponível em: $<$ http://www.educacao.rs.gov.br/dados/ens_med _proposta.pdf > Acesso em: 27 de maio 2013. 